\title{
CARACTERIZAÇÃO BIOMETRICA E BIOQUIMICA DE FRUTOS DE PHYSALIS IXOCARPA DURANTE O SEU DESENVOLVIMENTO
}

\author{
Josandra Souza Teles Fonseca $^{1}$; Claudinéia Regina Pelacani Cruz ${ }^{2}$; \\ Natália dos Santos Barroso ${ }^{3}$ e Mileide Santos Coutinho ${ }^{4}$ \\ 1. Bolsista PIBIC/ FAPESB, Graduando em Agronomia, Universidade Estadual de Feira de \\ Santana, e-mail: josandrateles@hotmail.com \\ 2. Orientadora, Departamento Ciências Biológicas, Universidade Estadual de Feira de Santana, e-mail: \\ claudineiapelacani@gmail.com \\ 3. Doutoranda, Recursos Genéticos Vegetais Universidade Estadual de Feira de Santana, e-mail: \\ nataliasbarroso@yahoo.com.br \\ 4. Mestre em Recursos Genéticos Vegetais Universidade Estadual de Feira de Santana, e-mail: \\ mileidecoutinho@yahoo.com.br
}

PALAVRAS-CHAVE: Maturação de frutos; colheita; teor de açúcar.

\section{INTRODUÇÃOO}

No Brasil, o desenvolvimento de cultivos frutíferos não tradicionais, tem despertado novos interesses de mercado, havendo ainda, inúmeras frutas nativas e exóticas pouco exploradas economicamente. Entre elas estão a atemóia, maná, canistel, mirtilo, lichia, carambola, Physalis entre outras (WATANABE; OLIVEIRA, 2014).

A Physalis pertence à família Solanaceae, possui cerca de 453 espécies, com 100 delas bem conhecidas (El SHEIKHA et al., 2010). Tem sido consumida como fruto exótico e com preço bastante elevado no mercado, variando nos anos de 2011 e 2012 de35 a 31 reais o quilograma de acordo com dados apresentados por Watanabe e Oliveira (2014).

Dentre as espécies de destaque no gênero encontra-se a espécie $P$. ixocarpa, amplamente utilizada em pratos tradicionais da culinária mexicana, extensivamente cultivada em regiões da América do Norte (HERNANDEZ e YANEZ, 2009). Apesar de espécies do gênero já serem conhecidas e comercializadas no Brasil, não se tem informações do cultivo e comercialização desta espécie no país.

Atributos físicos e químicos presentes em frutos são de grande valor para a sua comercialização, manuseio e fatores como aparência externa, tamanho, consistência, espessura, forma e coloração da casca (COSTA et al., 2004), bem como, a riqueza de nutrientes. Estes tornam aceitáveis e conduzem o interesse dos consumidores por frutas e seus subprodutos (RUFINO et al., 2010).

O estádio de maturação dos frutos de espécies de Physalis pode ser determinado a partir da presença de características fisico-químicas como coloração, peso, tamanho e teor de sólidos solúveis totais (LIMA et al., 2012). A principal característica desta fase, é a presença de um processo complexo e geneticamente programado, que resulta em alterações na coloração, no aroma, na textura e no flavor dos frutos, tornando-os aptos ao consumo (AYUB et al., 1996).

Assim, este trabalho objetiva acompanhar a maturação dos frutos de $P$. ixocarpa nas condições ambientais de Feira de Santana, através da caracterização física e bioquímica dos mesmos em diferentes estádios de maturação.

\section{METODOLOGIA}


Frutos de Physalis ixocarpa, foram produzidos no período de maio a agosto no Horto Florestal da Universidade Estadual de Feira de Santana.

A caracterização e processamento foi realizada em laboratório onde os frutos foram separados em cinco estádios de maturação segundo descrito por Barroso et al. (2017). Foi determinada a coloração dos cálices e frutos mediante a comparação com a tabela de cores da carta de cores RSH (RHS, 1995). Determinou-se também o peso fresco (g) com auxílio de balança analítica; diâmetros transversais (medida da região mediana) e longitudinais (medida do ápice a base) do fruto $(\mathrm{mm})$ usando paquímetro digital.

Após a caracterização, os frutos foram processados, centrifugados e o sobrenadante armazenada em ultrafreezer $\left(-80^{\circ} \mathrm{C}\right)$ para a realização análise bioquímicas. Determinouse o teor de sólidos solúveis com o auxílio do refratômetro digital os resultados foram expressos em ${ }^{\circ}$ Brix, teor de vitamina $\mathrm{C}$, determinado por meio da reação do ácido ascórbico com o 2,6-diclorofenol indofenol (DCFI) (OLIVEIRA, 2010), os açúcares totais pelo método da antrona (YEMM \& WILLIS, 1954) e açúcares redutores pelo método do dinitrosalicilato (DNS) (MILLER, 1959). As proteínas solúveis foram determinadas colorimetricamente baseando-se na mudança de cor de um reagente (azul brilhante de Coomassie) utilizando-se a albumina de soro bovino pura como padrão (BRADFORD, 1976).

Para as avaliações físicas e bioquímicas dos frutos foram utilizadas 5 repetições de 10 frutos para cada estádio ( $\mathrm{n}=50$ ). Realizou-se as análises bioquímicas em triplicata. Os resultados foram submetidos a analise de variância e as diferenças entre as médias comparadas pelo teste Tukey, $5 \%$ de probabilidade. A análise dos dados foi realizada por meio do programa computacional SISVAR (FERREIRA, 2011).

\section{RESULTADOS E DISCUSSÃO}

As tabelas 1 e 2 mostram os resultados obtidos pela caracterização e análise físicoquímica dos frutos de Physalis ixocarpa nos diferentes estágios de desenvolvimento. Observou-se que com o decorrer dos estádios de maturação houve um incremento no comprimento, diâmetro e peso dos frutos. Em se tratando de sólidos solúveis, foi encontrado um valor dentro do esperado para a espécie a partir no estádio 3, Brix próximo a $5^{\circ}$. (SILVA et al., 2016; BARROSO et al., 2017). Com relação a coloração dos cálices e dos frutos do estádio1 ao 4 observou-se predominância da coloração e verde amarelado e verde escuro respectivamente já no último estádio obteve-se coloração marrom amarelado claro e verde amarelado. Os açúcares redutores apresentaram maior teor nos frutos imaturos, estágio 1 com melhor média, já os açúcares redutores totais, em maior quantidade, foram encontrados em frutos maduros, estágio 4 com melhor teor. Para os valores de proteínas totais, foram encontrados, somente o estágio 3 maior teor os demais estádios tiveram suas médias reduzidas. Nesse estudo os teores de vitamina $\mathrm{C}$ observados, foram maiores nos frutos imaturos, nos estádios 1 e 2 .

Tabela 1: Comprimento (C), diâmetro (D), peso fresco (PF), sólidos solúveis totais (SST), cor do cálice (CC) e dos frutos (CF) em frutos de P. ixocarpa nos diferentes estádios de desenvolvimento. UEFS, Feira de Santana, BA, 2015.

\begin{tabular}{lllllll}
\hline Estádio & $\mathrm{C}$ & $\mathrm{D}$ & $\mathrm{PF}$ & $\mathrm{SST}$ & $\mathrm{CC}^{*}$ & $\mathrm{CF}^{*}$ \\
\hline
\end{tabular}




\begin{tabular}{lllllll}
\hline & $(\mathrm{mm})$ & $(\mathrm{mm})$ & $(\mathrm{g})$ & $\left({ }^{\circ}\right.$ Brix $)$ & & \\
\hline 1 & $11,4 \mathrm{~b}$ & $19,9 \mathrm{~d}$ & $22,3 \mathrm{e}$ & $2,5 \mathrm{~b}$ & $\mathrm{VA}$ & $\mathrm{VE}$ \\
2 & $14,2 \mathrm{~b}$ & $24 \mathrm{c}$ & $28,4 \mathrm{~d}$ & $3,4 \mathrm{~b}$ & $\mathrm{VA}$ & $\mathrm{VE}$ \\
3 & $19,5 \mathrm{~b}$ & $28,8 \mathrm{~b}$ & $34,3 \mathrm{c}$ & $4,6 \mathrm{a}$ & $\mathrm{VA}$ & $\mathrm{VE}$ \\
4 & $37,1 \mathrm{a}$ & $33,9 \mathrm{a}$ & $39,5 \mathrm{~b}$ & $5,2 \mathrm{a}$ & $\mathrm{VA}$ & $\mathrm{VE}$ \\
5 & $37,2 \mathrm{a}$ & $36,1 \mathrm{a}$ & $43,4 \mathrm{a}$ & $5,3 \mathrm{a}$ & $\mathrm{MA}$ & $\mathrm{VA}$ \\
\hline $\mathrm{CV} \mathrm{( \% )}$ & 22,4 & 5,6 & 4,2 & 11,8 & - & - \\
\hline
\end{tabular}

* VE : Verde escuro, VA : verde amarelado, MA : Marrom amarelado claro. Médias seguidas pela mesma letra na coluna para cada variável analisada não diferem entre si pelo teste de Tukey a 0,05 de probabilidade.

Tabela 2: Açúcar redutor (AR), Açúcares solúveis totais (AST), Proteínas solúveis totais (PT) e Vitamina $\mathrm{C}$ em frutos de P. ixocarpa nos diferentes estádios de desenvolvimento. UEFS, Feira de Santana, BA, 2015.

\begin{tabular}{lllll}
\hline Estádio & $\begin{array}{l}\text { AR } \\
\left(\mathrm{g} \cdot 100 \mathrm{~g}^{-1}\right)\end{array}$ & $\begin{array}{l}\text { AST } \\
\left(\mathrm{g} \cdot 100 \mathrm{~g}^{-1}\right)\end{array}$ & $\begin{array}{l}\mathrm{PT} \\
\left(\mathrm{g} \cdot 100 \mathrm{~g}^{-1}\right)\end{array}$ & $\begin{array}{l}\text { Vit C } \\
\left(\mathrm{mg} \cdot 100 \mathrm{~g}^{-1}\right)\end{array}$ \\
\hline 1 & $0,20 \mathrm{a}$ & $0,77 \mathrm{~b}$ & $0,89 \mathrm{~b}$ & $54,1 \mathrm{~b}$ \\
2 & $0,15 \mathrm{c}$ & $0,92 \mathrm{ab}$ & $0,73 \mathrm{c}$ & $158 \mathrm{a}$ \\
3 & $0,18 \mathrm{~b}$ & $1,12 \mathrm{ab}$ & $1,05 \mathrm{a}$ & $63,6 \mathrm{~b}$ \\
4 & $0,18 \mathrm{~b}$ & $1,65 \mathrm{a}$ & $0,98 \mathrm{ab}$ & $83,4 \mathrm{ab}$ \\
5 & $0,13 \mathrm{c}$ & $1,23 \mathrm{ab}$ & $0,97 \mathrm{ab}$ & $48,6 \mathrm{~b}$ \\
\hline $\mathrm{CV}(\%)$ & 3,8 & 24,9 & 5,5 & 28,2 \\
\hline
\end{tabular}

Médias seguidas pela mesma letra na coluna para cada variável analisada não diferem entre si pelo teste de Tukey a 0,05 de probabilidade.

Estes resultados indicam que durante o processo de maturação os frutos de Physalis ixorcarpa existem diversas transformações que ocorrem interna e externamente. Essas transformações são influenciadas por fatores fisiológicos e ambientais que podem modificar as características dos frutos, a exemplo do período de cultivo, adubação, ataque de pragas e doenças (LEMOS, 2016). O ponto de colheita dos frutos de Physalis é um fator muito importante para assegurar sua qualidade. Normalmente são colhidos quando maduros, sendo determinado pela mudança de coloração do fruto e do cálice que o envolve (RUFATO et al.,2008). Portanto, escolha do melhor período permite máximo aproveitamento pós-colheita do produto vegetal por apresentar melhor qualidade e mínimo de perdas, e permite maior retorno econômico ao produtor (CHITARRA, 1994).

\section{CONSIDERAÇÕES FINAIS}

$\mathrm{Na}$ região de Feira de Santana, os frutos de $P$. ixocarpa devem ser colhidos ao atingirem o quarto estádio de maturação, pois nesse estádio os frutos apresentarem características físicas e bioquímicas com maior qualidade para comercialização.

\section{REFERÊNCIAS}


BARROSO, N. S.; SOUZA, M. O.; RODRIGUES, L. C.S.; PELACANI, C. R. Maturation stages of fruits and physiological seed quality of Physalis ixocarpa Brot. ex hormen. Revista Brasileira de Fruticultura, Jaboticabal, v. 39, n. 3. 2017.

AYUB, R.; GUIS, M.; BEM-AMOR, M.; GILLOT, L.; ROUSTAN, J. P.; LATCHÉ, A.; BOUZAYEN, M.; PECH, J. C. Expression of ACC oxidase antisense gene inhibits ripening of cantaloupe melon fruits. Nature Biotechnology, London, v. 14, p. 862-866, 1996.

BRADFORD, M.M. A rapid and sensitive method for the quantitation of microgam quantities of protein utilizing the principle of protein-dye binding. Anal. Biochem., 72:24854,1976.

COSTA, N. P.; LUZ, T. L. B.; BRUNO, R. L. A. Caracterização físico-química de frutos de umbuzeiro (Spondias tuberosa) colhidos em quatro estádios de maturação. Bioscience Journal (Uberlândia), v. 20, n. 2, p. 65-71, 2004.

CHITARRA, M. I. F. Colheita e qualidade pós-colheita de frutos. Informe Agropecuário, Belo Horizonte, v. 17, n. 179, p. 8-18, 1994.

EL SHEIKHA, A. F.; PIOMBO, G.; GOLI, T.; MONTET, D. Main composition of Physalis (Physalis pubescens L.) fruit juice from Egypt. Fruits, v. 65, n. 4, p. 255-265, 2010.

FERREIRA, D. F. Sisvar: a computer statistic alanalysis system. Ciência e Agrotecnologia v. 35, p. 1039-1042, 2011.

HERNANDEZ, J. F. S. ; YANEZ, S. B. Aprovechamiento tradicional de las especies de Physalis en México. Revista de Geografía Agrícola, v. 43, p. 81-86, 2009.

LEMOS, O. L. Utilização de biofilmes comestíveis na conservação pós-colheita do pimentão 'Magali R'. 2006. 115 p. Dissertação (Mestrado em Agronomia) Universidade Estadual do Sudoeste da Bahia, Vitória da Conquista, 2006.

MILLER, G. L. Use of dinitrosalicilic acid reagent for determination of reducing sugar. Analytical Chemistry, v.31, p.426-428, 1959.

OLIVEIRA, L. A. Manual de Laboratório: análises físico-quimicas de frutas e mandioca. Embrapa Mandioca e fruticultura. Cruz das Almas- Ba, 2010

RUFATO, L. Aspectos técnicos da cultura da Physalis. Lages: CAV/UDESC; Pelotas:UFPel, 100p, 2008.

RHS.THE ROYAL HORTICULTURAL SOCIETY. colour chart. London: 2001. (4 fan)

SILVA, D. F.; PIO, R.L; SOARES, J. D. R.; ELIAS, H. H.S., VILLA, F.; VILAS

BOAS, E. V. B. Light spectrum on the quality of fruits of physalis species in subtropical area. Bragantia, Campinas, v. 75, n. 3, p. 371-376, 2016.

WATANABE, H. S.; OLIVEIRA, S. L. Comercialização de frutas exóticas. Revista Brasileira de Fruticultura, Jaboticabal, v. 36, n. 1, p. 23-38, 2014.

YEMM, E. W.; WILLIS, A. I. The estimation of carbohydrates in plant extracts by anthrone. Biochemical Journal, London, v. 57, p. 508-514, 1954. 